\title{
Cartas para la historia: El epistolario de los Carrillo de Albornoz y Bravo de Lagunas, condes de Montemar, en el ocaso del imperio español en América, 1761-1799
}

\author{
Antonio de Sotomayor* \\ Silvia Escanilla Huerta**
}

\section{INTRODUCCIÓN}

En este artículo pretendemos dar a conocer una importante colección de cartas para el estudio de la historia del imperio español de finales del siglo XVIII, ubicadas en la biblioteca de la Universidad de Illinois en UrbanaChampaign, Estados Unidos, pero subidas y en acceso gratuito en el portal llamado The Conde de Montemar Letters. ${ }^{1}$ Se trata de alrededor de 300 cartas de la familia del Conde de Montemar, Diego José Carrillo de Albornoz y Bravo de Lagunas V conde de Montemar, cubriendo desde 1761 a 1799. Este período que cubren las cartas coincide con importantes procesos ocurridos durante las últimas décadas del régimen español en América que incluyeron las reformas borbónicas, la expulsión de los Jesuitas, rebeliones indígenas (Túpac Amaru), y un creciente sentimiento de diferenciación entre criollos y peninsulares, entre otros. ${ }^{2}$ Dada la extensión del período y el perfil tan prominente de sus autores, pensamos que esta colección resulta de gran interés y amerita ser estudiada sistemáticamente.

La biblioteca de la Universidad de Illinois, una de las bibliotecas académicas más grandes en el mundo con más de 14 millones de volúmenes y 23

* Universidad de Illinois, Urbana-Champaign, Ilinois, Estados Unidos. Correo electrónico: asotomay@illinois.edu.ORCID: https://orcid.org/0000-0001-6795-8772.

** Universidad de Illinois, Urbana-Champaign, Ilinois, Estados Unidos. Correo electrónico: escanil2@illinois.edu. ORCID: https://orcid.org/0000-0001-7196-9490. https://quest.library.illinois.edu/Conde-de-Montemar-Letters/

2 Para un análisis general del período ver Kenneth Andrien y Allan Kuethe, The Spanish Atlantic World in the Eighteenth Century. War and the Bourbon Reforms 1713-1796, Cambridge, Cambridge University Press, 2014. 
millones de artefactos, adquirió esta colección en el año 2000 de un anticuario que las pudo conseguir en un estado de preservación excelente. Aunque las cartas están ubicadas en la sala de manuscritos y libros raros, pertenecen a la colección latinoamericana y caribeña, la cual cuenta con casi un millón de volúmenes y se considera entre las principales colecciones latinoamericanas y caribeñas en Norteamérica.

\section{EL SIGLO XVIII EN LA AMÉRICA ESPAÑOLA}

El siglo XVIII, escenario de este epistolario, fue tiempo de profundos cambios en el Imperio Español. Luego de una larga Guerra de Sucesión (17011713), el ascenso al trono español de la dinastía de los Borbón conllevó la búsqueda por renovar un desequilibrado imperio amenazado por el creciente poderío de varios reinados en Europa. ${ }^{3}$ En primer lugar, esta renovación implicó el que España atravesara un constante estado de guerra contra otras potencias europeas a lo largo del siglo XVIII. En segundo lugar, los monarcas españoles batallaron en contra de la noción de una España atrasada y de segunda clase. En su lugar, los Borbones intentaron reemplazar esta visión

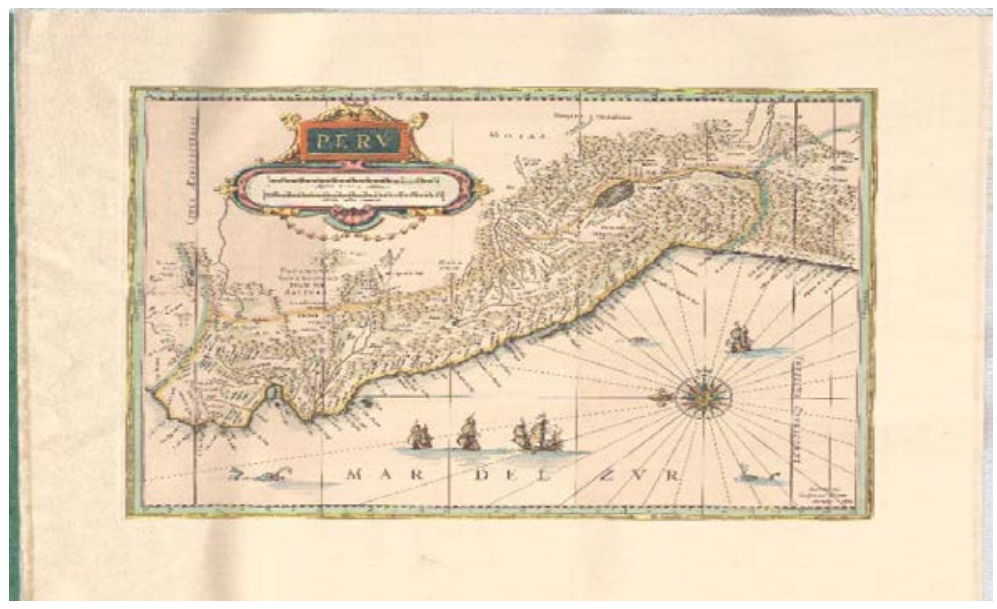

Figura 1. Mapa del Perú, 1659. Willem Janszoon Blaeu. Cortesía de IberoAmerikanisches Institut.

3 John H. Elliott, Empires of the Atlantic World: Britain and Spain in America 1492-1830, New Haven, Yale University Press, 2007. 
negativa con la imagen de un imperio reorganizado y próspero. Esta reorganización general del imperio se ha conocido como las "reformas borbónicas,” las cuales consistieron en la adaptación de políticas administrativas, fiscales, comerciales y militares que habían sido exitosas en imperios europeos rivales a la realidad española. ${ }^{4}$ En el contexto americano, las reformas fueron concebidas desde la cúpula de la administración imperial como una forma de reafirmar el control y la autoridad sobre los asuntos que habían estado en manos de administradores americanos hasta entonces. En efecto, con el comienzo del reinado de Carlos III en 1760 las políticas reales intentaron restringir el acceso de los administradores americanos a posiciones de control gubernamental, aumentando, del mismo modo, el control del comercio colonial desde Madrid. ${ }^{5}$

\section{LA NObleza EN El VirReinato Del PERÚ}

La élite limeña, un selecto grupo de familias poderosas enlazadas por matrimonio y afinidades sociales y económicas fue directamente afectada por estos cambios. Durante los siglos XVI y XVII, miembros de esta élite colaboraron con la corona para establecer un control efectivo sobre el territorio americano. En sus orígenes, muchos de los miembros originales de estas dinastías nobiliarias fueron nombrados en plazas administrativas y políticas claves dentro de la administración colonial. ${ }^{6}$ Esto a su vez generó diversas oportunidades de negocios que enriquecieron a sus familias, las que eventualmente adquirieron títulos nobiliarios. Las prácticas matrimoniales endogámicas sumadas a intereses económicos y políticos compartidos crearon fuertes redes sociales que conectaron familias a ambos lados del Atlántico. Estas redes sociales operaron bajo acuerdos tácitos que en última instancia fortalecieron la autoridad del rey a la par que reforzaron la lealtad de las élites americanas a la corona española. ${ }^{7}$ Esta fructífera asociación transatlántica se vio amenazada en la segunda mitad del siglo XVIII producto del giro centralista y la implementación de las reformas desde Madrid que afectaron la burocracia y la administración de los virreinatos en América.

4 Gabriel Paquette, Enlightenment, Governance, and Reform in Spain and its Empire, 17591808, London, UK, Palgrave Macmillan, 2008.

5 John Fisher, El Perú borbónico (1750-1824), Lima, IEP, 2000.

6 Yuen Gen-Liang, Family and Empire. The Fernández de Córdoba and the Spanish Realm. Philadelphia, University of Pennsylvania Press, 2011.

7 Diana Balmori, Stuart F. Voss, y Miles Wortman, Notable Family Networks in Latin America, Chicago and London, The University of Chicago Press, 1984. 


\section{LaS Reformas borbónicas en el Perú}

El terremoto que destruyó una gran parte de Lima y El Callao en 1746 fue percibido por pensadores políticos en Madrid como una oportunidad para reconstruir y reformar la ciudad de Lima. El virrey José Antonio Manso de Velasco, Conde de Superunda, quien estaba a cargo durante el terremoto, encauzó todos sus esfuerzos para reconstruir la ciudad. Sin embargo, tuvo que negociar con la poderosa élite limeña para llevar a cabo las reformas que tenía previstas en la ciudad. ${ }^{8}$ Asimismo, la Iglesia se opuso firmemente a los planes de Superunda porque incluían limitar la presencia física de la iglesia en la ciudad evitando reconstruir monasterios e iglesias cuyo número el virrey consideraba excesivo. Al final, el conflicto terminó en un empate en el que el único perdedor fue la Iglesia. En el proceso, el virrey Superunda forjó lazos amistosos con un sector de la élite local, cuyos miembros sirvieron al virrey como cuerpo concejal. El virrey que suplantó a Superunda, Manuel Amat y Junient renovó la presión política dirigida a limitar el poder de la élite limeña en los principales cargos administrativos del virreinato. ${ }^{9}$ Con este fin Amat reformó la audiencia y promovió a peninsulares como oidores en detrimento de los criollos que habían monopolizado dicha posición. ${ }^{10} \mathrm{El}$ virrey Amat fue muy exitoso en este trámite a pesar de que los cambios no fueron bienvenidos por la élite local, según resulta evidente en las cartas de la familia Carrillo de Albornoz.

La Rebelión de Túpac Amaru, también conocida como Gran Rebelión, la cual conmocionó el virreinato entre los años de 1780 y 1783 representó un momento clave tanto para la corona española como para la élite limeña. Tanto su extensión como el nivel de radicalización que alcanzó representaron un antes y un después en la política virreinal respecto de los sectores indígenas. ${ }^{11}$ Aunque la rebelión fue controlada y sus líderes ejecutados, el miedo a una latente insurrección indígena persistió generando cambios en la organización militar del virreinato. La creación de nuevos cuerpos de milicias favoreció a las familias nobles como los Carrillo de Albornoz, quienes

8

$$
\text { IFEA, } 2012 .
$$

9 Guillermo Lohmann Villena, Los ministros de la Audiencia de Lima en el reinado de los Borbones (1700-1821): Esquema de un estudio sobre un núcleo dirigente, Sevilla, Consejo Superior de Investigaciones Científicas, Escuela de Estudios Hispano-Americanos, 1974; Leon Campbell. "Creole Domination of the Audiencia of Lima during the Late Eighteenth Century”, Hispanic American Historical Review 52, no. 1, 1972, pp. 1-25.

10 Carlos Pardo-Figueroa Thays y Joseph Dager Alva (eds.), El virrey Amat y su tiempo, Lima, PUCP-Instituto Riva Agüero, 2004.

11 Sergio Serulnikov, Revolución en los andes. La era de Túpac Amaru, Buenos Aires: Sudamericana, 2010. 
reforzaron sus lazos con la corona española al ocupar los más altos puestos en los regimientos a lo largo del virreinato, particularmente en Cuzco, Arequipa y Trujillo. ${ }^{12}$ La continuación de rebeliones al comienzo del siglo XIX no hizo sino solidificar esta relación que se vería puesta a prueba en dos ocasiones diferentes, primero en España en 1808 y luego en Perú en $1820{ }^{13}$

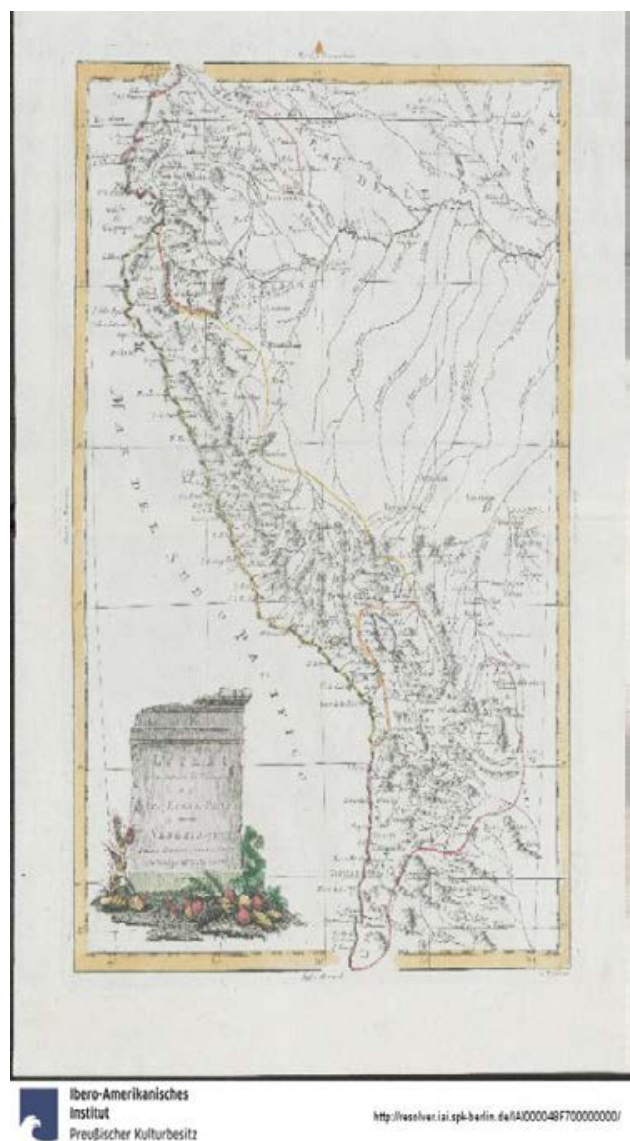

Figura 2. Mapa del Perú, 1785, Giovanni Marco Pitteri y Antonio Zatta. Cortesía del Ibero-Amerikanisches Institut.

12 Monica Ricketts, "The Rise of the Bourbon Military in Peru, 1768-1820", Colonial Latin American Review 21, no. 3, 2012, pp. 413-439.

13 Patricia Marks, Deconstructing Legitimacy. Viceroys, Merchants and the Military in Late Colonial Peru, Pennsylvania, Pennsylvania State University Press, 2007. 


\section{UN MUNDO DE CARTAS}

El siglo XVIII marcó un punto de inflexión en el sistema de comunicación entre España y América. ${ }^{14}$ Tradicionalmente, la Flota de Indias hacía la travesía desde España a los puertos de Veracruz, Cartagena y Portobelo en América transportando gente y mercancía dos veces al año. Desde Portobelo la Armada Española del Mar del Sur, una flota de galeones, continuaba el viaje hacia Perú para extraer la plata de Potosí. ${ }^{15}$ En el siglo XVIII una serie de guerras internacionales y la necesidad de mejorar las relaciones comerciales entre España y América llevó a la corona española a reformar el sistema de flotas. Luego de la destrucción de Portobelo en 1739, la corona permitió la navegación de navíos de registro individuales y navíos de aviso para conectar el virreinato del Perú con España a través de Panamá o Cabo de Hornos. Aunque estos barcos eran más pequeños que los galeones y no eran naves de guerra eran también más veloces por lo que permitían que la correspondencia llegara cada dos o tres meses en vez de cada seis meses.

Para evadir el peligro que conllevaban las travesías marítimas que habitualmente incluía extensos períodos de guerra, la amenaza de corsarios y la posibilidad cierta de naufragios, se popularizaron prácticas que buscaban garantizar la entrega de la correspondencia. ${ }^{16}$ Familias como los Carrillo de Albornoz solían enviar copias de la misma carta en barcos diferentes. Otra alternativa era copiar las partes más importantes de una carta dirigida a un familiar específico a sus parientes o amistades más próximas. Esto buscaba garantizar que la información contenida en correspondencia importante llegara al destinatario aunque se perdiera la original. Más aún, ya que las cartas eran tradicionalmente leídas en voz alta entre miembros de una familia y/o parientes cercanos, la información contenida en las cartas no era privada, y podía alcanzar un público mayor más allá de la familia. ${ }^{17}$ Finalmente, como ocurre en el caso de las cartas del Conde de Montemar, muchas veces las cartas eran numeradas para mantener un orden específico de lectura que solía verse alterado si los barcos se atrasaban. Si el destinatario recibía una carta cuyo número no era correlativo con la anterior, sabía a ciencia cierta que había otra carta en camino y podía movilizarse para ubi-

14 Eve Tavor Bannet, Empire of Letters: Letter Manuals and Transatlantic Correspondence, 1688-1820, Cambridge, Cambridge University Press, 2005.

15 Sylvia Sellers-García, Distance and Documents at the Spanish Empire's Periphery, Stanford, Stanford University Press, 2014.

16 Jeremy Baskes, Staying Afloat: Risk and Uncertainty in Spanish Atlantic World Trade, 1760-1820, Stanford, Calif., Stanford University Press, 2013.

17 Roger Chartier, et al., Correspondence. Models of Letter-Writing from the Middle Ages to the Nineteenth Century, Trans. Christopher Woodall, Princeton NJ, Princeton University Press, 1997. 
carla. Asimismo, la numeración de cartas ayudaba a mantener un registro de cuántas se estaban enviando y a quiénes. La mayor velocidad y frecuencia de la correspondencia hacía que estas cartas tuviesen un mayor impacto.

\section{ORÍGENES DE LA FAMILIA CARRILLO DE ALbORNOZY BRAVO DE LAGUNAS}

La familia Carrillo de Albornoz es de las más antiguas en España y su historia se remonta al siglo XII. ${ }^{18} \mathrm{Al}$ ser parte de la alta nobleza castellana, los Carrillo de Albornoz estuvieron muy envueltos en la administración gubernamental del reino. En 1694, Pedro Antonio Carrillo de Albornoz y Esquivel de Guzmán se convirtió en el primer conde de Montemar por gracia del rey Carlos II, quien lo recompensó por sus logros militares. Luego de fallecer sin sucesión, el título pasó a su hermano Fernando, quien lo pasó a su hijo José Carrillo de Albornoz y Montiel. José se convirtió en un héroe militar y fue recompensado con el virreinato de Sicilia, entre otras mercedes. Por sus servicios a la corona, Felipe V le otorgó el ducado de Montemar y el título de Grande de España (designación nobiliaria más alta del reino) en 1735. Luego de su muerte, la Grandeza de España y el ducado fueron transferidos a su única hija María Magdalena Carrillo de Albornoz y Antich, pero el condado y las atribuciones del mayorazgo correspondiente fueron transferidos a su primo hermano varón, Diego Miguel Carrillo de Albornoz y de la Presa IV conde de Montemar. Diego Miguel nació en Lima en 1695 y era hijo legítimo de Diego Bernardo Carrillo de Albornoz y Esquivel de Guzmán, nacido en Sevilla y con una brillante carrera militar, y Rosa María de Santo Domingo de la Presa y Manrique de Lara, nacida en Lima y descendiente de prominentes linajes nobles del reino. Esta rama de la familia Carrillo de Albornoz había llegado al Perú a finales del siglo XVII, y sus miembros habían ocupado puestos privilegiados en el virreinato, tales como el de regidor de Panamá y Lima, escribano mayor de la Mar del Sur, capitán de caballos en 1720, maestre de campo de los ejércitos reales, coronel de un regimiento de caballería y corregidor y alcalde de Lima en 1737 y $1738 .{ }^{19} \mathrm{El}$ 21 de julio de 1723 Diego Miguel casó con Mariana Bravo de Lagunas y Villela, Señora del Castillo de Mirabel, y juntos tuvieron los siguientes hijos: Rosa María, Diego José (V Conde de Montemar), Fernando (VI Conde de

18 Alonso Carrillo, Epitome del origen y descendencia de los Carrillos, Lisboa, Antonio Alvarez, 1639.

19 Endika de Mogrobejo, Irantzu de Mogrobejo y Garikoitz de Mogrobejo (eds.), Diccionario hispanoamericano de heráldica, onomástica y genealogía, vol. XXXIV (XIX), Bilbao, Editorial Mogrobejo-Zabala, 2007, pp. 5-43. 
Montemar), Juan Bautista, Clara María, Pedro José, Lucía, José, Juan Antonio, Manuel, e Isabel.

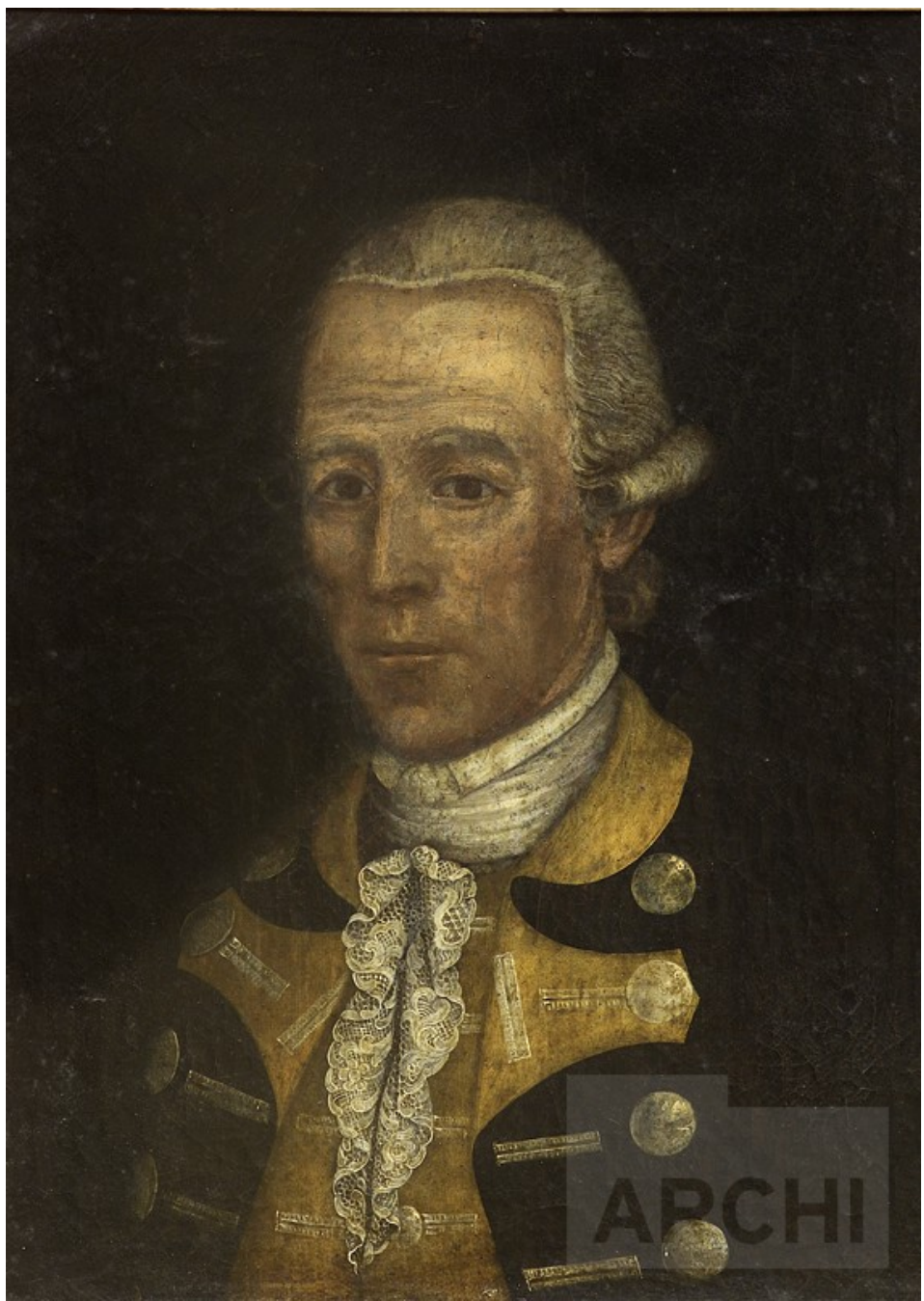

Figura 3. Retrato de Fernando Carrillo de Albornoz y Bravo de Lagunas, VI Conde de Montemar. Imagen cortesía del Archivo Digital de Arte Peruano. 


\section{ACTIVIdAd Económica y Política}

La mayoría de las cartas en esta colección fueron escritas por Diego José Carrillo de Albornoz y Bravo de Lagunas y su hermano Pedro. Diego asumió el condado de Montemar luego de que su padre Diego Miguel falleciera el 5 de febrero de 1750, siendo también Señor del Castillo de Mirabel. Al ser el primogénito, Diego José heredó el mayorazgo de su padre. ${ }^{20} \mathrm{El}$ hermano de Diego José, Fernando, quien eventualmente heredaría el condado de Montemar, también tenía alto poder y privilegios en el virreinato, siendo regidor perpetuo y heredando de Diego José el señorío del Castillo de Mirabel, coronel del regimiento de caballería de la provincia de Chincha, caballero de la Orden de Montesa, en la que ingresó el 21 de enero de $1791,{ }^{21}$ alcalde de la Santa Hermandad y juez del ramo de Temporalidades, una posición judicial muy privilegiada. Como juez, Fernando tenía garantizado acceso directo y sin obstrucciones a las propiedades de la orden de los Jesuitas, las cuales fueron confiscadas por la corona en 1767 cuando la orden fue expulsada de América. ${ }^{22}$ Del mismo modo, Fernando era un importante terrateniente con propiedades que incluían las haciendas de San Regis, San José, Hoja Redonda y la Playa, la mayor parte de éstas en Chincha, al sur de Lima. Su matrimonio con Rosa de Salazar y Gabiño, quien se convirtió en condesa de Monteblanco, fue un éxito económico porque ella trajo al matrimonio una dote que consistía en varias propiedades. Juntos, Fernando y Rosa fueron dueños de más de un millar de esclavos. ${ }^{23} \mathrm{El}$ historiador Paul Rizo-Patrón Boylan ha estudiado a fondo estas familias de la alta nobleza peruana y ha demostrado el poderoso nivel de la familia Carrillo de Albornoz. ${ }^{24}$ Sin embargo, en sus estudios no ha hecho mención de estas cartas como fuentes, por lo que éstas pueden ser de gran utilidad para entender el alcance de esta familia y su impacto.

La colección Montemar también tiene varias cartas escritas por Pedro Carrillo de Albornoz y Bravo de Lagunas, hermano de Diego José. Pedro era coronel del regimiento de caballería de milicias provinciales urbanas de la villa de Huaura, en la provincia de Chancay y caballero de la Orden de Mon-

Magdalena Chocano, “Linaje y mayorazgo en el Perú colonial”, Revista del Archivo General de la Nación, 12, 1995.

21 Mogrobejo, Mogrobejo y Mogrobejo, Diccionario hispanoamericano, p. 41.

22 Cristóbal Aljovín de Losada, "Los compradores de las Temporalidades a fines de la colonia”, Histórica 14, núm. 2, 1990, pp. 183-233.

23 Paul Rizo-Patrón Boylan, “Grandes propietarias del Perú virreinal: las Salazar y Gabiño”, en Margarita Guerra et al., Historias paralelas: Actas del primer encuentro de Historia PerúMéxico, Lima, PUCP, 2005.

24 Paul Rizo-Patrón Boylan, Linaje, dote y poder: La nobleza de Lima de 1700 a 1850, Lima, Pontificia Universidad Católica del Perú, Fondo Editorial, 2000, pp. 76-77. 
tesa, ${ }^{25}$ y heredero de las propiedades de su tía Isabel de la Presa en Lima. Entre los conflictos familiares internos cubiertos en las cartas está la disputa entre Diego José y Pedro sobre el testamento de su tía, el cual duró alrededor de una década. Pedro casó con Josefa de Salazar y Gabiño, la segunda hija del conde de Monteblanco y hermana de la esposa de Fernando. A través de su matrimonio adquirió la hacienda de San Ildefonso de Guaito, donde se producía caña de azúcar y que contaba con una fuerza laboral de alrededor de 600 esclavos. Era dueño también de la quinta de la Presa en Lima y de un molino de pólvora.

Aunque la familia Carrillo de Albornoz pertenecía a la nobleza de Lima, eran activos productores y comerciantes, ya que estaban envueltos en la producción de azúcar y vino, e importaban trigo desde Chile. ${ }^{26}$ Fernando también importaba mulas desde Tucumán en el Río de la Plata y era dueño de una panadería y un almacén de gran tamaño en Bellavista, entre Lima y el puerto del Callao. Asimismo, ocuparon cargos en la administración colonial, siendo el corregimiento el puesto preferido por varios hermanos. Dado que estas jurisdicciones reales administraban un área que solía comprender entre ocho y quince parroquias constituían una fuente de ingresos seguros a quien estuviera a cargo. ${ }^{27}$ Por ello, en diferentes momentos los hermanos compitieron y obtuvieron los corregimientos de Aimaraes, Huanta, Huamanga y Sica Sica. También contaban de forma hereditaria con un puesto en el cabildo de la ciudad de Lima.

\section{UN MUNDO DE CONEXIONES}

Las cartas de la colección Montemar ofrecen una oportunidad única para acceder al mundo de la nobleza en la América Hispana de finales del siglo XVIII. La familia Carrillo de Albornoz estaba muy conectada tanto por sangre como por matrimonio con la mayoría de las familias prominentes en el virreinato y en la península. ${ }^{28}$ Más aún, a través de estas conexiones estaban enlazados con los oficiales de la corona en Lima y en Madrid. Según se puede observar en las cartas, Diego José fue un personaje regular dentro de la corte real. Allí cultivó relaciones amistosas con varios miembros promi-

27 Alfredo Moreno Cebrián, El corregidor de indios y la economía peruana en el siglo XVIII (los repartos forzosos de mercancías), Madrid, Consejo Superior de Investigaciones Científicas, Instituto Gonzalo Fernández de Oviedo, 1977.

28 Balmori, Voss y Wortman, Notable Family Networks in Latin America. 
nentes del consejo de Castilla y el consejo de Indias, incluyendo a Pedro Rodríguez de Campomanes, Eugenio Salcedo y Pedro Pablo Abarca de Bolea conde de Aranda, entre otros. Diego José también cultivó relaciones amistosas, y frecuentemente visitó otras familias limeñas, incluyendo a los Valdelirios, quienes también vivían en Madrid en aquel entonces.

\section{LAS CARTAS Y SU ACCESO}

Como un recurso único, las cartas varían en extensión, algunas son de unas cuatro páginas y otras de hasta 22 (Figura 4). Se estima que hay unas 4 mil o 5 mil imágenes subidas a la página web, pues las cartas incluyen fotos de cada página y de cada folio. Se han seguido normas muy estrictas de catalogación y metadatos para identificar cada imagen y su espacio dentro de la colección mayor. En la sección "The Letters" se encuentran las primeras 32 cartas, las cuales se hallan en la primera caja de la colección física. Estas primeras 32 cartas, que van desde 1761 a 1765, han sido transcritas diplomáticamente para facilitar estudios paleográficos y su lectura en general (Figura 5). En la parte superior y al pie de esta sección en la página web encontrarán un enlace a la colección completa en la Biblioteca Digital de la Universidad de Illinois. En esta sección las cartas no cuentan con transcripción (Figura 6), pero sí se provee información del destinatario y remitente, al igual que el lugar de origen de la carta y otros detalles (Figura 7). Cada imagen cuenta con su propio esquema de catalogación y con herramientas para agrandar la imagen.

Para ofrecer una muestra de la riqueza de información que estas cartas proveen para estudios históricos se han preparado dos tablas. La primera detalla los nombres de individuos mencionados en las primeras siete cartas y su parentesco con Diego José, V Conde de Montemar (Tabla 1). La segunda presenta los nombres de lugares mencionados en las primeras ocho cartas y en cual/es carta/s aparecen (Tabla 2). Como se puede observar en estas dos tablas, una muestra pequeña del contenido de estas cartas nos deja ver cuán amplias fueron las conexiones de esta familia. En las primeras siete cartas se mencionan 42 personas, la gran mayoría perteneciente a la nobleza tanto en España como América y/o personas de alto rango administrativo dentro del gobierno colonial. Igualmente significante, en las primeras ocho cartas se mencionan 35 lugares, distribuidos tanto entre lugares esperados como $\mathrm{Li}$ ma, Madrid, Europa, América, como lugares más especiales como Azángaro, Aimaraes, Conchucos, Roma y Gibraltar, entre otros.

En conclusión, entendemos que el valor de estas cartas para el estudio histórico del mundo hispano a finales del siglo XVIII es incalculable. El proyecto digital que hace accesible estas cartas no sólo llama la atención de 
los investigadores hacia recursos para la historia hispano-americana poco conocidos aún, sino que también pone de manifiesto el potencial de las humanidades digitales para hacer disponibles estos recursos al mundo.

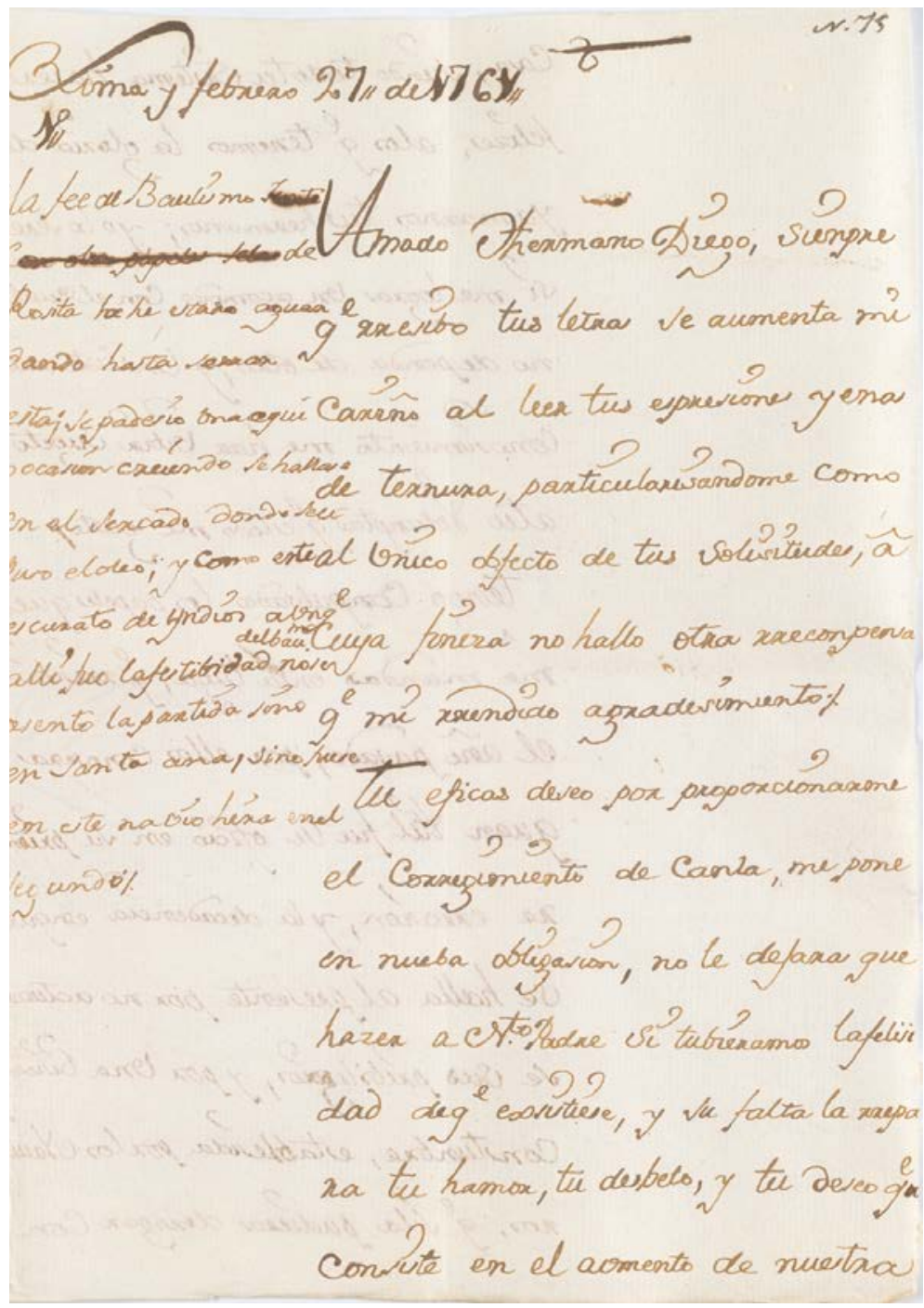

Figura 4. Primera página de la primera carta de la colección Montemar. 
Letter from Pedro Carrillo de Albornoz y Bravo de Lagunas to Diego José , Fifth Count of Montemar

Summary

Pedro tells Diego José about his brothers and sisters' activities. He provides information about some errands he had to run and mentions he is sending their brothers' birth certificates except for Rosita's that he is still looking for. He is also sending their great grandfather's will for Diego to take notice of some details of the mayorazgo he has inherited. Pedro mentions a rebellion in Apongo his brother Juan has had to deal with. He is thankful to Diego José for trying to obtain a Corregimiento in Canta for him. Finally Pedro mentions a past disagreement between his brother Fernando and Diego José but he hopes they can be in good terms again soon.

Sent: Pedro Received: Diego José, Lima, Peru, 27 de Febrero de 1761

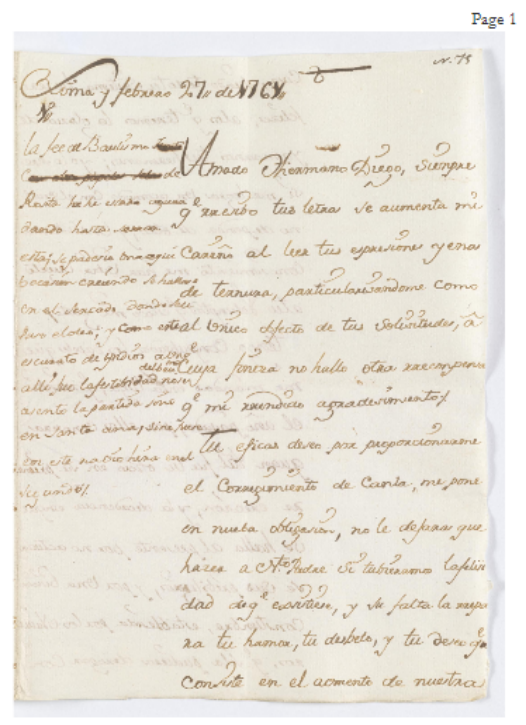

Lima y Febrero 27" de 1761"

La fee de Bautismo junte

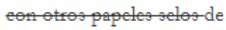

Rosita la he estado aguardando hasta serrar esta; se padesio una equibocacion creiendo se hallase en el sercado donde sele puso el oleo; $y$ como este es curato de yndios aunque alli fue lafestibidad no se asento la partida sino en santa ana, sino fuese en este navio hira en el segundo $\%$
Amado Hermano Diego, siempre $q^{2}$ rresibo tus letras se aumenta mi cariño al leer tus espresiones yenas de ternura, particularisandome como al unico objecto de tus solisitudes, â cuya fineza no hallo otra rrecompensa $q^{e}$ mi rendido agradesimiento \% Tu eficas deseo por proporcionarme el corregimiento de Canta, me pone en nueba obligacion, no le dejara que hazer a $N^{\text {to }}$ Padre si tubieramos la felisidad deq ${ }^{c}$ existiese, $y$ su falta la rrepara tu hamor, tu desbelo $\mathrm{y}$ tu deseo $q^{e}$ consiste en el aumento de nuestra

\footnotetext{
University of Illinois at Urbana-Champaign Rare Book and Manuscript Library

Conde de Montemar Correspondence POST-1650 MS 0135
}

Figura 5. Captura de imagen de la primera página de la primera carta de la colección Montemar y su transcripción diplomática. 


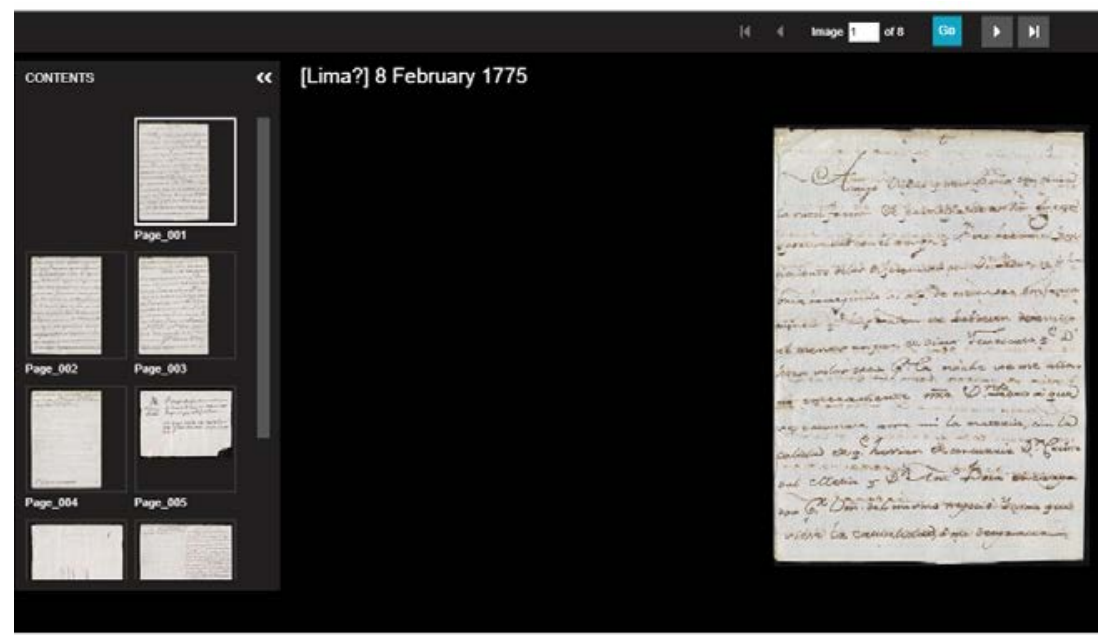

Figura 6. Captura de carta del 8 de febrero de 1775.

(2) UNIHE THATES

\section{$\boxminus$ Descriptive Information}

\begin{tabular}{ll} 
Title & [Lima?] 8 February 1775 \\
\hline Sent & Lara \\
\hline Date & $1775-02-08$ \\
\hline Year & 1775 \\
\hline Extent & 3 leaves \\
\hline Type & Image Q \\
\hline Spatial Coverage & Lima (Peru) Q \\
\hline Language & spa \\
\hline Repository & University of Illinois at Urbana-Champaign. Rare Book and Manuscript Library \\
\hline Collection Title & Conde de Montemar Letters \\
\hline Physical Location & $01 / 02 / 02 / P 0 S T-1650$ MS 0135, Box 3, folder 75 \\
\hline Image ID & 5318583 box 3 f75 \\
\hline Rights Statement & No Copyright - United States
\end{tabular}

\section{$\boxplus$ Download}

Figura 7. Captura de imagen de metadatos de carta del 8 de febrero de 1775 . 


\section{Tabla 1}

Parentescos del V Conde de Montemar, Digo José Carrillo de Albornoz y Bravo de Lagunas según mencionados en las primeras siete cartas de la colección

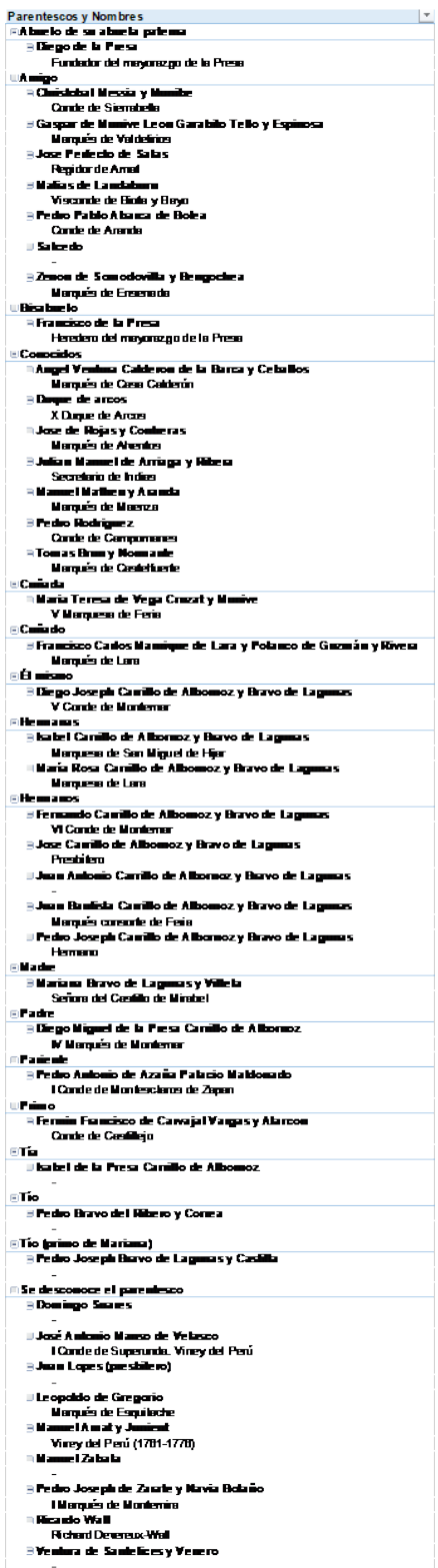


Tabla 2

\section{Nombres geográficos mencionados en las primeras 8 cartas}

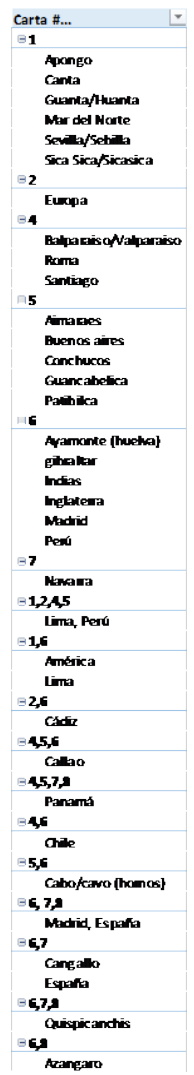

\section{Bibliografía}

Aljovín de Losada, Cristóbal, "Los compradores de las Temporalidades a fines de la colonia, Histórica 14, núm. 2, 1990, pp. 183-233.

Andrien, Kenneth y Allan Kuethe, The Spanish Atlantic World in the Eighteenth Century. War and the Bourbon Reforms 1713-1796, Cambridge, Cambridge University Press, 2014.

Balmori, Diana, Stuart F. Voss, y Miles Wortman, Notable Family Networks in Latin America, Chicago, The University of Chicago Press, 1984.

Bannet, Eve Tavor, Empire of Letters: Letter Manuals and Transatlantic Correspondence, 1688-1820, Cambridge, Cambridge University Press, 2005. 
Baskes, Jeremy, Staying Afloat: Risk and Uncertainty in Spanish Atlantic World Trade, 1760-1820, Stanford, California: Stanford University Press, 2013.

Campbell, Leon, "Creole Domination of the Audiencia of Lima during the Late Eighteenth Century”, Hispanic American Historical Review 52, no. 1, 1972, pp. 1-25.

Carrillo, Alonso. Epitome del origen y descendencia de los Carrillos, Lisboa, Antonio Alvarez, 1639.

Chartier, Roger et al., Correspondence. Models of Letter-Writing from the Middle Ages to the Nineteenth Century, Trans. Christopher Woodall, Princeton, New Jersey, Princeton University Press, 1997.

Chocano, Magdalena, “Linaje y mayorazgo en el Perú colonial”, Revista del Archivo General de la Nación, núm. 12, 1995.

Elliott, John H., Empires of the Atlantic World: Britain and Spain in America 1492-1830, New Haven, Yale University Press, 2007.

Fisher, John, El Perú borbónico (1750-1824), Lima, IEP, 2000.

Gen-Liang, Yuen, Family and Empire. The Fernández de Córdoba and the Spanish Realm, Philadelphia, University of Pennsylvania Press, 2011.

Lohmann Villena, Guillermo, Los ministros de la Audiencia de Lima en el reinado de los Borbones (1700-1821): Esquema de un estudio sobre un núcleo dirigente., Sevilla: Consejo Superior de Investigaciones Científicas, Escuela de Estudios Hispano-Americanos, 1974.

Marks, Patricia, Deconstructing Legitimacy, Viceroys, Merchants and the Military in Late Colonial Peru, Pennsylvania: Pennsylvania State University Press, 2007.

Mogrobejo, Endika de, Irantzu de Mogrobejo y Garikoitz de Mogrobejo (eds.), Diccionario hispanoamericano de heráldica, onomástica y genealogía, vol. XXXIV (XIX), Bilbao, Editorial Mogrobejo-Zabala, 2007, pp. 5-43.

Moreno Cebrián, Alfredo, El corregidor de indios y la economía peruana en el siglo XVIII (los repartos forzosos de mercancías), Madrid, Consejo Superior de Investigaciones Científicas, Instituto Gonzalo Fernández de Oviedo, 1977.

Paquette, Gabriel, Enlightenment, Governance, and Reform in Spain and its Empire, 1759-1808, London, UK, Palgrave Macmillan, 2008.

Pardo-Figueroa Thays, Carlos y Joseph Dager Alva (eds.), El virrey Amat y su tiempo, Lima, PUCP-Instituto Riva Agüero, 2004.

Ricketts, Monica, “The Rise of the Bourbon Military in Peru, 1768-1820”, Colonial Latin American Review 21, no. 3, 2012, pp. 413-439.

Rizo-Patrón Boylan, Paul, Linaje, dote y poder: La nobleza de Lima de 1700 a 1850. Lima: Pontificia Universidad Católica del Perú, Fondo Editorial, 2000.

, “Grandes propietarias del Perú virreinal: las Salazar y Gabiño”, en Margarita Guerra et al., Historias paralelas: Actas del primer encuentro de Historia Perú-México, Lima, PUCP, 2005. 
Serulnikov, Sergio, Revolución en los andes. La era de Túpac Amaru, Buenos Aires, Sudamericana, 2010.

Sellers-García, Sylvia, Distance and Documents at the Spanish Empire's Periphery, Stanford, Stanford University Press, 2014.

Walker, Charles, Colonialismo en ruinas. Lima frente al terremoto y tsunami de 1746, Lima, IFEA, 2012. 